Sustentare, Três Corações, v. 1, n. 1, p. 93-107, ago./dez. 2017

\title{
DIAGNÓSTICO DOS PROBLEMAS OPERACIONAIS DAS ESTAÇÕES DE TRATAMENTO DE ESGOTO DAS UNIDADES PRISIONAIS DA REGIÃO METROPOLITANA DE BELO HORIZONTE, MG
}

\author{
Shirley Soares de OLIVEIRA ${ }^{1}$; Marcelo da FONSECA ${ }^{2}$; Izabel Cristina de Matos \\ ANDRADE $^{3}$; Sérgio Ricardo MAGALHÃES ${ }^{4}$; Eliana ALCANTRA ${ }^{5}$
}

\begin{abstract}
${ }^{1}$ Graduanda em Engenharia Civil pelo Centro Universitário Metodista Izabela Hendrix (CEUNIH), e-mail: shirleydelorma@yahoo.com.br

${ }^{2}$ Mestre em Engenharia Civil. Docente no Centro Universitário Izabela Hendrix (CEUNIH), e-mail: marcelo.fonseca@izabelahendrix.edu.br

${ }^{3}$ Mestre em Saneamento, Meio Ambiente e Recursos Hídricos. Docente da Universidade Vale do Rio Verde (UninCor), email: prof.izabel.andrade@unincor.edu.br

${ }^{4}$ Doutor. Docente na Universidade Vale do Rio Verde (UninCor), e-mail: sergio.magalhaes@unincor.edu.br

${ }^{5}$ Doutora. Docente da Universidade Vale do Rio Verde (UninCor), e-mail: prof.eliana.alcantra@ unincor.edu.br
\end{abstract}

Recebido em: 10/05/2017-Aprovado em: 10/07/2017 -Disponibilizado em: 30/12/2017

\begin{abstract}
Resumo: O saneamento básico é essencial para assegurar uma boa qualidade de vida e está diretamente ligado à água, pois, além do consumo, a água também faz parte de várias atividades exercidas pelo homem. O saneamento no Brasil ainda é uma grande problemática urbana e ambiental. Somente $20 \%$ do esgoto produzido no Brasil são tratados, ou seja, $80 \%$ são despejados em rios, lagos, mares e mananciais. Nestas mesmas condições, também se encontra o sistema prisional de Minas Gerais, que sofre com a falta de saneamento em seus presídios e penitenciárias. Este trabalho apresenta um estudo de caso sobre os problemas operacionais das estações de tratamento de esgoto (ETE) de duas unidades prisionais da Região Metropolitana de Belo Horizonte, por meio de uma revisão bibliográfica sobre o tema, baseada em livros e normas. Além disso, promoveu-se uma avaliação comparativa dos seguintes aspectos: requisitos normativos (NBR 12209) x projeto, projeto x execução, bem como de uma avaliação sobre os problemas operacionais baseados em visitas in loco e relatórios operacionais. Os resultados mostram que as ETEs possuem baixas ou nenhuma eficiência, em consequência das falhas de projeto e de operação.
\end{abstract}

Palavras-chave:Saneamento básico. Problemas Operacionais. Saúde pública. Impactos ambientais.

\begin{abstract}
The basic sanitation is essential to ensure a quality of life, and it is directly connected to water, beyond consumption, the water makes part of several activities that are performed by the man. The sanitation in Brazil is a big urban and environmental problem yet, just $20 \%$ of all produced sewage in Brazil are treated, then, $80 \%$ are dumped in rivers, lakes, oceans and fountains. Also found in these same conditions the prison system of Minas Gerais, that suffer with the lack of sanitation in its prisons and penitentiaries. The present work shows a study of case about the operational problems in the sewage treatment station (STS) of two prison units in the metropolitan region of Belo Horizonte, by means of a revision about the theme, based on books and standards. Besides a comparative evaluation of such aspects: regulatory requirements (NBR 12209) vs. project vs. execution, as well, an evaluation about operational problems based on visits and operational report. The results show that the (STS) have a little or no efficiency, in consequences of project deficiencies and operation.
\end{abstract}

Keywords:Basic sanitation. Operationalproblems. Publichealth. Environmental impacts.

\section{INTRODUÇÃO}

\section{Ao longo da história, a preocupação}

com o saneamento sempre esteve

relacionada à transmissão de doenças e à degradação ao meio ambiente. Na primeira metade do século XX, quando a superlotação dos domicílios urbanos, e o alto índice de epidemias agravadas pela desnutrição, afetava grande parte da população. Isso fez com que os governantes começassem a se preocupar 
com saúde dos habitantes das cidades, considerando as doenças uma preocupação social e determinando a adequação das condições de salubridade no ambiente das cidades por meio deinstalação de tratamento de água, canalização do esgoto e controle das epidemias (AYACH, 2012).

No Brasil, até a década de 1930, Oswaldo Cruz grande pesquisador que atuou como cientista, médico, bacteriologista, epidemiologista e sanitarista brasileiro. Foi o pioneiro no estudo de doenças tropicais e da medicina experimental no Brasil. Contribuiu muito com suas pesquisas, fazendo com que a saúde ocupasse um lugar central na agenda pública,oportunizando uma grande preocupação política quanto à questão sanitária. Nesse mesmo período houve um significativo aumentodo abastecimento de água nas cidades. Já a visão higienista de Saturnino de Brito foi o engenheiro sanitarista brasileiro, que realizou alguns dos mais importantes estudos de saneamento básico e urbanismo em várias cidades do país, sendo considerado o "pioneiro" da Engenharia Sanitária e Ambiental no Brasil, gerou mudanças no uso detecnologias em sistemas de esgotamento, passando a ser implantado o sistema separador absoluto (AZEVEDO, 1984).

Outro marco foi a elaboração do
Código das Águas em 1934 apresentou as primeiras diretrizes para a gestão dos recursos hídricos no país, dando prioridade ao abastecimento público. Nas décadas de 50 e60, várias legislações Federais e Estaduais foram promulgadascom intenção de estabelecer classificações e parâmetros da qualidade da água, mas nenhuma ainda os relacionava explicitamente com os benefícios do saneamento e a saúde. Somente na década de 70, com o Plano Nacional de Saneamento (PLANASA), essa relação ficou clara, onde o plano tinha como objetivo a melhoria dos índices de atendimento da população por sistemas de abastecimento de água e comvisão de que avanços no esgotamento sanitário e na qualidade da água levada à população resultariam na diminuição das taxas de mortalidade(COPASA, 2012).

$$
\text { Mesmo cientesda grande }
$$
importância do saneamento básico, é fato que, um dos maiores problemas ambientais no Brasil ainda é exatamente a falta dele. O acúmulo de resíduos sólidos em local indevido e o esgotamento sanitário inadequado pode propiciar a contaminação do solo e mananciais, além daproliferação de doenças (CAVINATO, 2003).

De acordo com os dados do Ministério das Cidades (Sistema Nacional de Informações sobre Saneamento - SNIS) em 2013, 82,5\% dapopulação brasileira era 
| Sustentare, Três Corações, v. 1, n. 1, p. 93-107, ago./dez. 2017

abastecida com água tratada, ou seja, mais de 35 milhões de pessoas não possuíam este serviço. No que diz respeito à coleta de esgotos, 48,6\% da população recebia atendimento, o que totaliza quase 100 milhões de brasileiros sem esse serviço. Mais grave ainda é a situação do tratamento dos esgotos em que, segundo dados do SNIS, apenas 39\% do esgoto coletado são tratados, os outros $61 \%$ são lançados na natureza (SNIS, 2014).

A falta de saneamento também é um problema para a população carcerária mineira, que representa a segunda maior população prisional do Brasil com 61.392 detentos. Os sistemas prisionais de Minas Gerais, segundo dados da Secretaria de Estado de Defesa Social (SEDS), não possuem sistemas adequados de coleta, tratamento e disposição do esgoto sanitário produzido nas unidades. Exemplos desta realidade são as unidades prisionais localizadas nos municípios de São Joaquim de Bicas e Ribeirão as Neves, que lançam o esgoto diretamente no curso d'água mais próximo (SEDS, 2015).

A gravidade do assunto já motivou o Ministério Público do Estado de Minas Gerais (MPE) a abrir procedimentos para apurar essa omissão do Governo de Minas, como consta nos autos do Inquérito Civil Público 0231.07.000168-1 instaurando pela $6^{\circ}$ Promotoria de Justiça de Ribeirão das Neves, no qual o MPE interroga a Secretaria de Estado de Defesa Social (SEDS), por meio do Inquérito Civil Público 0231.07.000168-1 da $6^{\circ}$ Promotoria de Justiça de Ribeirão das Neves, sobre a operação da Estação de Tratamento de Esgoto (ETE), bem como, solicita informações sobre o tratamento e destinação dos efluentes. Já nos autos da Ação Civil Pública $\mathrm{n}^{\circ}$ 0087285.47.2012.8.13.0301 sobre a ETE do Complexo Penitenciário de São Joaquim de Bicas, são solicitados esclarecimentos sobre o lançamento do esgoto in natura no rio Paraopeba (SEDS, 2015).

A proposta desse trabalho foi identificar os problemas operacionais das ETEs das unidades prisionais da RMBH e propor diretrizes para os projetos de novas ETE's construídas pelo estado de Minas Gerais. A solução deste problema é importante para a qualidade de vida da população interna e externa às unidades prisionais nos municípios de São Joaquim de Bicas e Ribeirão das Neves, buscando melhorar as questões ambientais, econômicas e sociais de quem vive nesses municípios.

O presente projeto de pesquisa fazse oportuno para o momento, por se tratar de uma realidade no Estado de Minas Gerais. O desempenho operacional das 
Sustentare, Três Corações, v. 1, n. 1, p. 93-107, ago./dez. 2017

ETEs das unidades prisionais ainda é desconhecido, o que faz esse trabalho ser inédito e, nesse sentido considera-se de grande relevância para a área de saneamento do sistema prisional, pois será avaliado o desempenho das ETEs em operação nas unidades prisionais da $\mathrm{RMBH}$, fornecendo informações reais quanto ao desempenho do processo de tratamento, em termos da qualidade e especificidade do efluente gerado e da eficiência de sua operação. Pois, tais projetos aparentam não atender às particularidades do sistema carcerário, comprometendo deste modo, o desempenho operacional dos sistemas de tratamento de esgoto destas unidades.

\section{MATERIAL E MÉTODOS}

Buscando basear o estudo dentro da realidade do sistema prisional, foi realizada uma pesquisa in loco nas unidades prisionais em estudo, além de consultas a leis e livros, onde foram adotados três critérios de avaliação: análise de projetos, análise de execução e análise de operação. De posse dos dados comparativos foram levantadas as inadequações encontradas e propostas as adequações pertinentes.

\subsection{Locais de estudo}

Foram estudadas as estações de tratamento das unidades prisionais localizadas em São Joaquim de Bicas e Ribeirão das Neves, na Região Metropolitana de Belo Horizonte (RMBH), em Minas Gerais. Todas as unidades apresentam um funcionamento inadequado das ETE, segundo dados da SEDS (2016), e devido à proximidade com os cursos d'água, todas fazem o lançamento in natura diretamente nos cursos d'água próximos.

\subsubsection{Unidade de Ribeirão das Neves- Presídio Inspetor José Martinho Drumond}

Localizada na Rod. MG06, KM05, Fazenda dos Lajes, Ribeirão das Neves, a unidade foi inaugurada em fevereiro de 2009, e dispõe de uma área total de 22 mil metros quadrados com capacidade para 820 detentos. Possui 96 celas coletivas para oito presos e 52 celas individuais, e conta com um efetivo de 370 agentes penitenciários. Atualmente a unidade está com uma capacidade quase três vezes superior ao projetado, atualmente com 2075 detentos (SAIG, 2016). 
Figura 1: Localização do Presídio Inspetor José Martinho Drumond

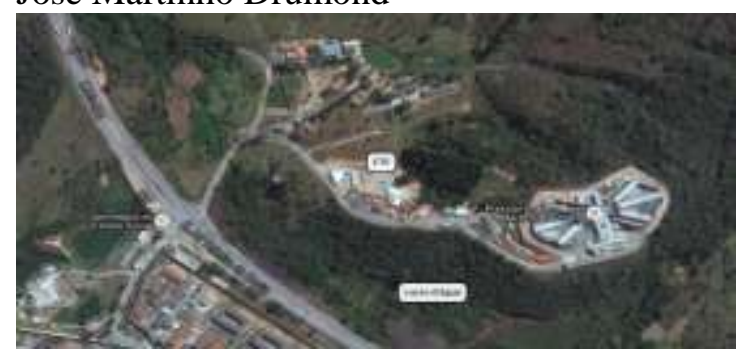

Fonte: Autores (2016)

\subsubsection{Unidades de São Joaquim de Bicas}

No município de São Joaquim de Bicas, no bairro Primavera, encontra-se o Complexo Penitenciário composto por três unidades prisionais (SEDS, 2012).

\section{a) Penitenciária Professor Jason Soares Albergaria - PPJSA}

Foi inaugurada em 2003. Projetada para 396 vagas masculinas, funciona com regime fechado e semiaberto. Atualmente, a penitenciária conta com uma população carcerária de 631 detentos (SAIG, 2016).

\section{b) Presídio São Joaquim de Bicas I- PRSJB}

Inaugurado em 2007, a unidade foi construída para a criação de novas vagas e para a transferência de detentos de outras unidades que se encontravam em estado de superlotação (SEDS, 2016). A unidade foi projetada para capacidade de 820 vagas masculinas e, atualmente, a unidade conta com uma população carcerária de 2025 detentos, quase três vezes superior à sua capacidade (SAIG, 2016).

\section{c) Presídio São Joaquim de Bicas II - PRSJBII}

Inaugurada em 2009, com capacidade de 594 detentos entre masculino e feminino. Atualmente, a unidade conta com 1768 encarcerados, ou seja, com uma lotação três vezes superior à sua capacidade (SEDS, 2016).

Figura 2: Localização das Unidades de São Joaquim de Bicas

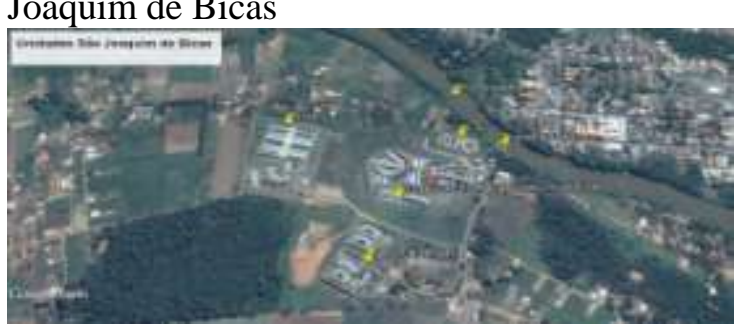

Fonte: Autores (2016)

\subsection{Análise dos projetos}

Nesta etapa, verificou-se se os projetos utilizados pelo Governo de Minas Gerais para a construção das referidas ETE's atendiam às exigências da NBR12209 (ABNT, 2011) a qual fixa condições para a elaboração de projetos de estações de tratamento de esgoto. Para fins dessa análise, as informações dos projetos foram comparadas com os seguintes itens normativos: Condições gerais (item 4), Critérios e disposições (item 5), Tratamento da fase líquida (item 6), Tratamento do lodo (item 7), Desinfecção (item 8) e Controle de emissões gasosas (item 9). 


\subsection{Análise das execuções}

Buscou-se verificar se as estações foram construídas conforme projeto. Devido às limitações de fiscalização da execução, que não produziram o relatório as built (como construído), a análise limitou-se a considerar se a população atual está compatível com a população de projeto, a capacidade operacional e se todas as unidades previstas no projeto foram executadas.

\subsection{Análise das operações}

Para aferir o desempenho operacional, foram realizadas três visitas in loco, nos meses de agosto/2016, setembro/2016 e outubro/2016, todas devidamente registradas por meio de relatórios fotográficos. Durante as visitas, foram observados os seguintes aspectos: a limpeza no entorno da ETE, a limpeza do gradeamento primário e as características do esgoto produzido nas unidades prisionais.

Além das visitas, a operação das estações foi avaliada por meio do Formulário de Controle Mensal de Operação das Estações de Tratamento de Esgoto. Tais formulários são preenchidos pelas unidades prisionais e encaminhados periodicamente para a SEDS. Os formulários permitiram a verificação das vazões, os horários de pico, o desempenho operacional e também avaliar o conhecimento dos operadores sobre a dinâmica operacional das estações de tratamento de esgoto.

\section{RESULTADOS}

\subsection{Análise de projetos}

O resultado da conferência dos critérios normativos de projetos (NBR 12209) encontra-se apresentado no Quadro 01 , onde "atende" indica o atendimento do critério e "não atende" o não atendimento ou a ausência da informação no memorial de projeto.

No caso da Unidade São Joaquim de Bicas, os projetos analisados estão em acordo com os requisitos normativos, com exceção das informações quanto à DBO e DQO em que não existe um plano de descarte do lodo após o leito de secagem. No caso da separação de sólidos por meios físicos, existem sistemas de gradeamento de $15 \mathrm{~mm}$ e peneira estática de $5 \mathrm{~mm}$, possui desarenação para remoção mínima de $95 \%$ de particulados igual ou superior a $0,2 \mathrm{~mm}$, e também possui decantação primária. A filtração biológica foi projetada para funcionamento do reator do tipo UASB. 
Quadro 01 - Comparação dos critérios de projeto

\begin{tabular}{|c|c|c|}
\hline Critérios Normativos & São Joaquim de Bicas & Ribeirão das Neves \\
\hline \multicolumn{3}{|c|}{ Condições gerais (item 4) } \\
\hline População & Atende & não atende \\
\hline Local de implantação & Antede & não atende \\
\hline Sondagem do subsolo & Antede & não atende \\
\hline Características do efluente & Antede & não atende \\
\hline Padrões de lançamento & Antede & não atende \\
\hline Comparação técnico-econômica & Antede & não atende \\
\hline Projetos hidráulico-sanitário & Antede & não atende \\
\hline \multicolumn{3}{|c|}{ Critérios e disposição (Item 5) } \\
\hline Vazão máxima e média & Antede & não atende \\
\hline Demanda bioquímica de oxigênio & não atende & não atende \\
\hline Demanda química de oxigênio & não atende & não atende \\
\hline Sólidos em suspensão & Antede & não atende \\
\hline Bay-pass & Antede & antede \\
\hline Mecanismos de medição de vazão & Antede & não atende \\
\hline Acesso facilitado & Antede & antede \\
\hline Dispositivos de segurança & Antede & antede \\
\hline \multicolumn{3}{|c|}{ Tratamento da fase líquida (Item 6) } \\
\hline Sepação de sólidos & Antede & antede \\
\hline Decantação & Antede & antede \\
\hline Sistema filtrante & Antede & antede \\
\hline \multicolumn{3}{|c|}{ Tratamento do lodo (Item 7) } \\
\hline Sistema de desinfecção & não atende & não atende \\
\hline Leito de secagem & Antede & antede \\
\hline Destinação & não atende & não atende \\
\hline \multicolumn{3}{|c|}{ Desinfecção (Item 8) } \\
\hline Sistema de desinfecção & não atende & não atende \\
\hline \multicolumn{3}{|c|}{ Controle de emissões gasosas (Item 9) } \\
\hline Sistema de controle & Antede & antede \\
\hline
\end{tabular}


Como indicado no Quadro 01, a Unidade de Ribeirão das Neves, não está de acordo com os projetos analisados. Não foram encontrados os requisitos de estudo de concepção, não há projeto de vazões máxima e média, não há dados para características de efluente tratado e não há relatório de sondagem do subsolo. Os únicos projetos existentes são: ETE planta e corte, tratamento preliminar das comportas, gradeamento, calha Parshal, reatores planta e corte, filtro biológico, tanque corta chamas, queimador, planta de implantação e leito de secagem, e projeto de edificação de apoio o cômodo (laboratório/ operação).

\subsection{Análise das execuções}

A ETE da Unidade São Joaquim de Bicas foi construída segundo seus projetos executivos, com exceção da edificação de apoio, conhecida como laboratório, que não foi executada por completo. Existe apenas a estrutura física, mas não dispõe de equipamentos, vidrarias e reagentes de laboratório, indispensáveis para a realização das análises mínimas de controle operacional do efluente lançado no rio Paraopeba. A Caixa d'água Tipo Taça são dispositivos com capacidades de armazenamento que variam entre 3 mil e 1 milhão de litros, e são encontradas nos modelos coluna seca e com água na coluna, variando de acordo com a necessidade de pressão sobre a água. A taça d'água foi instalada é a modelo coluna seca, mas a rede hidráulica não foi executada. A empresa executora apresentou o manual de operação e manutenção da ETE.

Na Unidade de Ribeirão das Neves, a ETE foi construída conforme os projetos apresentados, mas, segundo a unidade, não há registro do manual de operação e manutenção da ETE.

\subsection{Análise de operação}

Para análise do desempenho operacional das ETE's, foram avaliados os formulários de acompanhamento mensal, bem como realizadas visitas in loco. Os principais problemas operacionais e deficiências de projeto, constata nos períodos de inspeção e monitoramentos são apresentados abaixo.

\subsubsection{Unidade São Joaquim de Bicas}

a) $\mathrm{Na}$ chegada do esgoto bruto há um grande volume de materiais sólidos provindo de vários setores da unidade. O gradeado não é limpo com a periodicidade necessária, gerando a acumulação de grandes volumes como mostra na Figura 3a.

b) A limpeza é feita pelos detentos sob a 
instrução do agente penitenciário. Foi observado que, nem o agente nem o detento possuem conhecimento mínimo necessário para tal tarefa, pois, em vários horários, observou-se que o gradeado estava com acúmulo de resíduos, com presença de insetos, animais e materiais caídos na área externa ao gradeado como mostra na Figura $3 b$.

c) O material retirado do gradeado é armazenado de forma inadequada e deficiente, sendo este lançado a céu aberto no terreno atrás da ETE e próximo ao canil, levando a presença e proliferação de insetos e urubus, ilustrados na Figura 3c.

d) A ETE é operada por profissionais sem o devido treinamento. $\mathrm{O}$ mesmo ocorre com as atividades de manutenção, que são realizadas por detentos sob a supervisão dos agentes penitenciários. Quando a unidade é acometida de rebelião ou de falta de efetivo de agentes, os detentos ficam proibidos de executá-los, pois é indispensável a presença de um agente.

e) A eficiência do sistema de tratamento não é aferida, pois não existe material de laboratório para a realização de análises do efluente que é lançado no corpo receptor.

f) Durante o período avaliado (agosto a outubro de 2016) a ETE funcionou até dia 23 de setembro de 2016, estando atualmente paralisada devido aos problemas operacionais e lançando, portanto, o esgoto diretamente no rio Paraopeba.

g) Não existe um plano de disposição final para o lodo gerado no tratamento. O lodo gerado é disposto no terreno a céu aberto atrás da ETE.

h) O segundo gradeado é de $5 \mathrm{~mm} \mathrm{e}$ retém a maior parte do material orgânico que deveria ir para o tanque equalizador o que compromete a geração de gás, como mostra na Figura 3d. 
Figuras 3: ETE Unidade São Joaquim de Bicas a) Primeiro gradeamento, b) Limpeza Gradeamento, c) Local de disposição dos resíduos do gradeamento e d) Segundo gradeado.

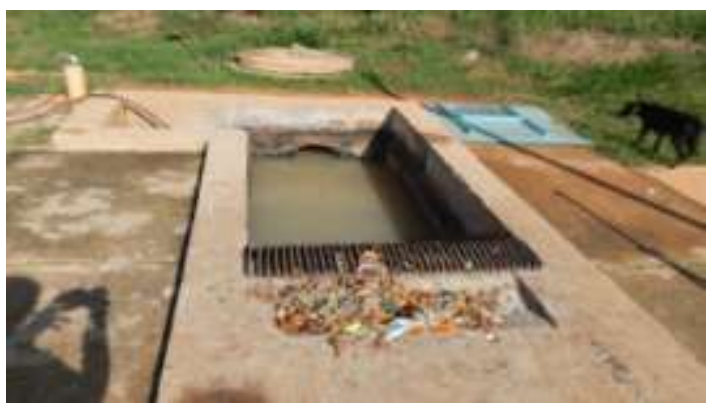

(a)

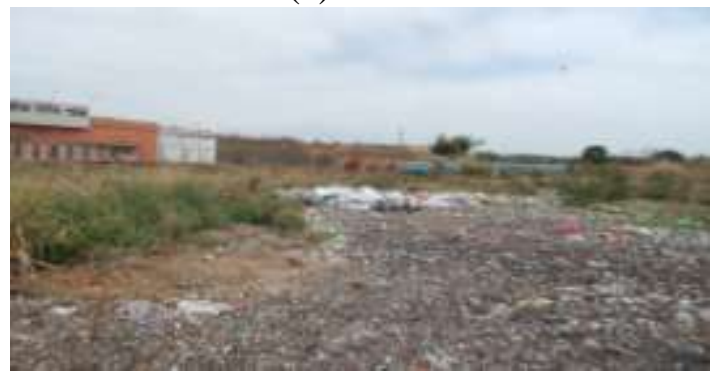

(c)

Fonte: autores (2016)

\subsubsection{Unidade Inspetor José Martinho Drumond}

a) $\mathrm{Na}$ chegada do esgoto bruto, o espaço, reservado para o gradeado é muito estreito e raso para processar o grande volume recebido, conforme Figura 4a. Devido a essa incompatibilidade, foi detectado que o sistema trabalha parcialmente, na caixa principal de chegada onde existe um by-pass que fica parcialmente aberto, lançando metade do esgoto diretamente no córrego, conforme Figura 4b.

b) A limpeza também é feita por detentos,

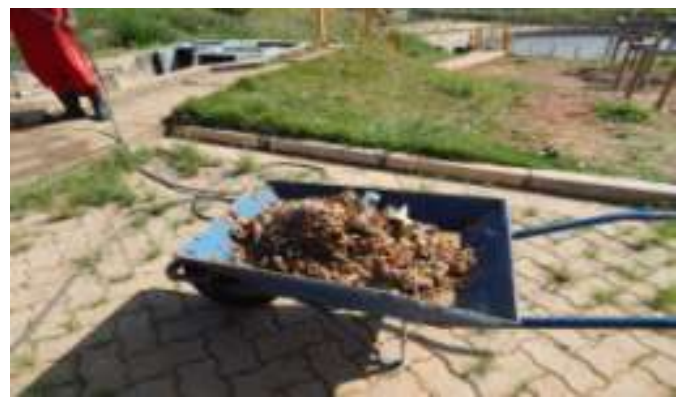

(b)

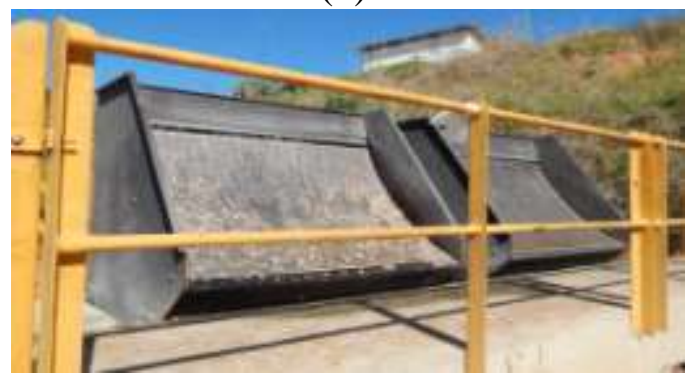

(d)

sob a supervisão de um agente Foi observado que a frequência de limpeza é adequada, porém, nos finais de semana há um déficit nos serviços, devido à falta de efetivo e aos horários de visita.

c) O material retirado do gradeado é enviado junto com lixo comum para a caçamba da prefeitura,

d) Não existe pessoal com treinamento adequado para operar e manter o sistema de tratamento funcionando adequadamente. A utilização de detentos para a realização dessas tarefas sem o necessário treinamento 
não tem levado a bons resultados. Quando a unidade é acometida de rebelião ou de falta de efetivo de agentes, os detentos ficam proibidos de executá-los, pois é indispensável a presença de um agente.

e) A eficiência do sistema de tratamento não é aferida, pois não existe material de laboratório para a realização de análises do efluente que é lançado no corpo receptor.

f) Durante o período avaliado (agosto a outubro), a ETE funcionou de forma parcial lançando metade do esgoto direto no córrego Cacique.

g) Não existe um plano de disposição final para o lodo gerado no tratamento. O lodo gerado é disposto junto ao lixo comum coletado pela prefeitura.

Figura 4: ETE Presídio Inspetor José Martinho Drumond a) Gradeamento b) Bay-pass

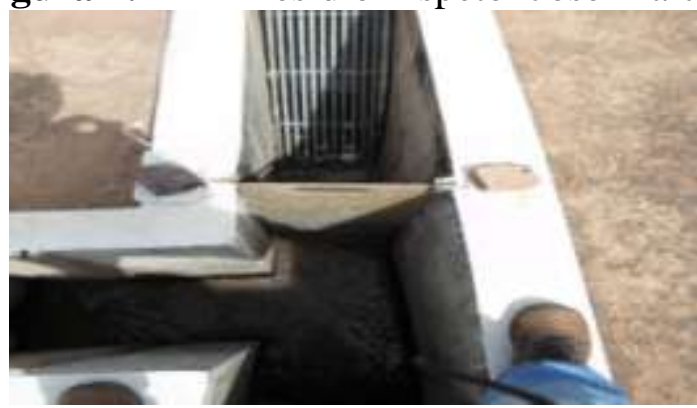

(a)

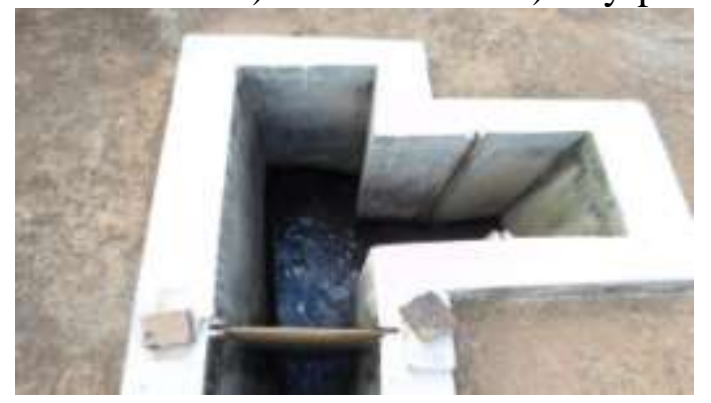

(b)

Fonte: autores (2016)

\section{DISCUSSÃO DOS RESULTADOS}

No caso dos projetos em conformidade com a NBR 12209 (ABNT, 2011), observou-se que as empresas contratadas apresentaram os projetos conforme termo de referência do processo licitatório. No que se refere à unidade Inspetor José Martinho Drumond, os estudos de concepção para o sistema de tratamento não foram apresentados. A contratada (Polyplaster) apresentou apenas o projeto de ETE para o tratamento do esgoto sanitário para 2000 habitantes. Os demais projetos ficaram sob a responsabilidade da contratante, no caso a SEDS, tais como os projetos de terraplanagem, as contenções e a estabilidade de taludes, o relatório de diretrizes, os projetos elétrico e estrutural que, por motivos desconhecidos, não foram localizados.

Na unidade de São Joaquim de Bicas, em conformidade com o contrato firmado entre a COPASA e a Tecminas Engenharia LTDA, os relatórios de estudos 
| Sustentare, Três Corações, v. 1, n. 1, p. 93-107, ago./dez. 2017

para concepção do sistema de tratamento foram todos apresentados, bem como os estudos geotécnicos, o relatório de diretrizes, o projeto básico, os projetos de especificações técnicas e de obra, o orçamento e os projetos elétrico e estrutural, em conformidade com a NBR 12209.

Segundo Nuvolari (2011), os estudos de concepção possuem significativa importância, pois é por meio deles que se identificam as características do esgoto que será tratado, qual sistema de tratamento adequado a ser implantado, na análise do corpo receptor, na qualidade do efluente tratado e outras diretrizes. No caso de sistemas de tratamento, tais estudos assumem uma maior significância, em função das especificidades do esgoto gerado.

Em decorrência dos hábitos da população carcerária, vários tipos de objetos são lançados na rede sanitária e também há um grande volume de efluente nos horários de "pico", o que acarreta um aumento na vazão e na presença de materiais sólidos grosseiros. Devido a esse aumento da vazão e de resíduos sólidos, o sistema de gradeamento presente na chegada do esgoto bruto não se mostrou suficiente no caso das duas unidades, para reter esses materiais, tais como resto de refeição não consumida, pedaços de pano, como uniformes e cobertores, gordura provinda da cozinha, guimbas de cigarro, e a grande quantidade de plástico. A passagem desses materiais pelo gradeamento compromete os equipamentos, acarretando o entupimento das bombas de recalque e assim comprometendo todo o funcionamento da ETE, como afirma Von Sperling (2005).

Outro problema observado referese ao dimensionamento da população usuária do sistema. As ETE's foram projetadas para atender o número de vagas do projeto modelo padrão SEDS. Como todas as unidades em estudo estão com superlotação, numa vazão três vezes superior ao valor de sua capacidade padrão, fora a população flutuante, a eficiência do sistema de tratamento fica comprometida. Foi detectado também que as redes de águas pluviais são lançadas na rede de esgotamento sanitário o que leva nos dias chuvosos a um incremento do grande volume de água e aporte de areia, pois, segundo Novulari (2011), é impresindível o estudo da população usuária da ETE.

O comparativo das obras executadas com os seus respectivos projetos indica que as obras foram executadas em acordo com os projetos conforme NBR 12209 (ABNT, 2011), mas como exposto acima, não basta apenas 
| Sustentare, Três Corações, v. 1, n. 1, p. 93-107, ago./dez. 2017

dimensionar a ETE de forma padrão. Nos projetos, deveriam ser consideradas as particularidades do sistema penitenciário, como aponta Von Sperling (2005).

As estações de tratamento de esgoto das unidades prisionais de São Joaquim de Bicas e Ribeirão das Neves, embora recentemente implantadas, encontram-se com suas eficiências comprometidas em consequência das deficiências de projeto e de operação. Tais inconformidades estão, em sua grande maioria, associadas à falta de estudo de concepção de projetos ou a um estudo deficiente. Nos casos em estudo, o grande volume de água e de materiais sólidos não orgânicos foram subdimensionados, comprometendo todo o sistema.

A existência de um convênio SEDS x COPASA, que abrange alguns serviços de manutenção, não vem se mostrando eficiente, pois o setor de fiscalização e manutenção não dá o devido apoio às unidades. A falta de profissional especializado foi detectada nas duas unidades em estudo. A manutenção é feita por detentos, com supervisão de agentes penitenciários que também não tiveram nenhum treinamento para operar a ETE.

\section{CONSIDERAÇÕES FINAIS}

Com a realização do presente estudo, foi possível perceber a grande dificuldade que as unidades possuem para operar as ETE's de forma adequada. Sendo assim, para a construção de uma ETE em uma unidade prisional, além da escolha do sistema, que deve abranger a eficiência do sistema, confiabilidade, custo, disponibilidade de área e a disposição final do lodo, deve-se também considerar a simplicidade de operação. A melhor alternativa sempre será aquela que possuir como requisito a observância da realidade local.

Como forma de minimizar os impactos, sugerem-se as seguintes medidas para adequar a operação das ETE's, até que medidas estruturantes (adequação física e ampliação das ETE's) sejam implantadas:

a) Instalação dos sistemas de gradeamento em série, permitindo a retenção de materiais sólidos, ou associar um triturador rotativo de barras, e também aumentar a frequência de limpeza das grades;

b) A construção de caixas equalizadoras de volume resolveria o problema de abertura do by-pass, pois a caixa reteria o volume inicial e manteria a vazão 
constante.

c) Dar destinação ambientalmente adequada aos resíduos segregados no sistema de gradeamento, e também para o lodo produzido na ETE;

d) A utilização de detentos para a realização das tarefas operacional, sem treinamento e supervisão, não tem produzido bons resultados. Recomenda-se a designação de um profissional específico, devidamente capacitado, para operar e promover a manutenção do sistema de tratamento;

e) A presença de um profissional específico seria interessante para acompanhar o efluente lançado no corpo receptor, bem como a manutenção adequada.

f) Promover, de imediato, o reparo ou a substituição dos equipamentos danificados.

\section{REFERÊNCIAS}

AYACH, Lucy Ribeiro; et al. Saúde, saneamento e percepção de riscos ambientais urbanos. Caderno de Geografia. São Paulo, v.22, n.37, p 4 - 26, 2012.

AZEVEDO, José M.N. et al. Sistemas de Esgoto Sanitários, 2 ed. São Paulo, FHSPUSP,1984, p 4-5.

ABNT. NBR 12.209: Elaboração de projetos hidráulico-sanitários de estações de tratamento de esgotos sanitários.

Associação Brasileira de Normas Técnicas. Rio de Janeiro, RJ. 2011.

BRASIL. Ministério de Meio Ambiente. Conselho Nacional do Meio Ambiente. Resolução CONAMA No 357 de 17 de março de 2005. Dispõe sobre a classificação dos corpos de água e diretrizes ambientais para o seu enquadramento, bem como estabelece as condições e padrões de lançamento de efluentes, e dá outras providências. Diário Oficial da União, Brasília, DF, nº 053, de 18/03/2005, págs. 58-63.

CAVINATTO, Vilma Maria. Saneamento básico: Fonte de saúde e bem estar. 2 . ed. São Paulo: Moderna, 2003, p 67- 87.

Companhia de Saneamento de Minas Gerais. Curso de Capacitação de Procedimentos Operacionais de Esgoto Sanitário. COPASA, elaboração: Heloisa Grego et al. Belo horizonte, 2012, 410p.

NUVOLARI, Ariosvaldo. Esgoto Sanitário, coleta, transporte, tratamento e reuso agrícola. 2 ed., 2011.

Secretaria de estado de defesa Social.

Subsecretaria de Administração Prisional, Belo Horizonte, SEDS, Diário do Executivo - 25/02/2012 p. 7, col. 3.

Secretaria de estado de defesa Social.

Subsecretaria de Administração Prisional, Belo Horizonte, SEDS, Diário do Executivo - 30/01/2015 p. 4, col. 1.

Secretaria de estado de defesa Social. Subsecretaria de Administração Prisional, Belo Horizonte, SEDS, Diário do Executivo - 28/03/2016 p. 2, col. 2.

SAIG. Superintendência de Articulação Institucional e Gestão de Vagas, Mapa 
Sustentare, Três Corações, v. 1, n. 1, p. 93-107, ago./dez. 2017

Carcerário Semanal, Belo Horizonte,

SAIG. Diário do Executivo - 30/01/2016

p. 4, col. 1.

SNIS. Sistema Nacional de Informações

sobre Saneamento. Secretaria Nacional de

Saneamento Ambiental, 2014.

VON SPERLING, M. Introdução à

Qualidade das Águas e ao Tratamento

de Esgotos. Belo Horizonte: Editora

UFMG, 2005. 